\title{
A menina e o menino que brincavam de ser...: representações de gênero e sexualidade em pesquisa com crianças*
}

\author{
CONSTANTINA XAVIER FILHA \\ Universidade Federal de Mato Grosso do Sul
}

O presente texto tem por objetivo descrever e analisar dados de pesquisa-ação realizada com crianças em uma escola pública municipal na cidade de Campo Grande/ MS. As ações fazem parte de uma pesquisa mais ampla, em andamento, com apoio do Conselho Nacional de Desenvolvimento Científico e Tecnológico (CNPq), que apresenta duas abordagens teórico-metodológicas: a bibliográfica e a pesquisa-ação.

A primeira propunha-se coletar, analisar e catalogar livros para a infância com as temáticas da sexualidade, gênero e diversidades.

A segunda, com crianças, teve o intuito de propiciar momentos de reflexão e questionamento sobre as temáticas privilegiadas no projeto, mediadas por livros, e produzir coletivamente materiais educativos para/com crianças.

No presente artigo, serão detalhados os pressupostos teórico-metodológicos e os desafios da realização de pesquisa com crianças, os aspectos coletados em uma das atividades realizadas e sua análise, bem como o processo de produção coletiva de material educativo para/com crianças; finalmente, além de outros resultados da pesquisa, a discussão teórica das representações coletadas. O referencial teórico que embasa a análise procede dos estudos culturais, dos estudos feministas e de pressupostos foucaultianos.

\footnotetext{
* Parte deste texto foi apresentada como comunicação oral na 34a Reunião Anual da Associação Nacional de Pós-Graduação e Pesquisa em Educação (ANPEd), 2011, no Grupo de Trabalho Gênero, Sexualidade e Educação (GT-23).
} 


\section{PRESSUPOSTOS TEÓRICO-METODOLÓGICOS DA PESQUISA: DESAFIOS DA PRODUÇÃO DE PESQUISA COM CRIANÇAS}

A coleta dos livros para a infância, objeto do primeiro eixo da pesquisa, encontra-se em fase de finalização. Até o momento, foram coletados mais de 500 títulos escritos em língua portuguesa, publicados de 1930 até 2010. Os livros foram selecionados in loco - em bibliotecas públicas e particulares de vários locais do Brasil (nos estados Mato Grosso do Sul e Rio Grande do Sul; e também em São Paulo, Campinas, Rio de Janeiro e Brasilia), incluindo aí a Biblioteca Nacional do Rio de Janeiro -, além da aquisição de livros novos e usados (compra pessoal e on-line). $\mathrm{O}$ produto final desse eixo da pesquisa constituirá um catálogo digital, com indicação sobre as obras analisadas, visando à socialização e posterior consulta de pessoas interessadas em suas temáticas.

Desse montante de títulos, foram selecionados 200 livros para serem disponibilizados às crianças na pesquisa-ação. Houve a divisão nas seguintes categoriais temáticas: 2 livros sobre AIDS; 11 sobre amor e enamoramento; 42 sobre diferenças, identidades e diversidades; 28 sobre contos e recontos de fadas; 36 sobre sexualidades e corpo; 39 sobre famílias; 12 sobre gênero; e, finalmente, 30 sobre violência e direitos humanos de crianças. Nove ${ }^{1}$ deles foram analisados mais detidamente com as crianças; os demais foram disponibilizados em rodas de leitura para posterior discussão.

Os momentos de pesquisa-ação foram desenvolvidos em encontros semanais com duração de quatro horas, em dias diferentes, em cada uma das duas salas de aula do $5^{\circ}$ ano do ensino fundamental $\left(5^{\circ} \mathrm{A}\right.$ e $\left.5^{\circ} \mathrm{B}\right)$ de uma escola pública municipal, no período matutino. As crianças (e alguns/as pré-adolescentes/adolescentes) tinham em média entre 10 e 15 anos de idade (a maioria entre 10 e 11 anos).

A pesquisa-ação ocorreu de agosto a dezembro de 2010. Antes de seu início, foi feita a sua apresentação à equipe de direção da escola para autorização, e depois a todo o corpo docente que estaria atuando no período de realização da pesquisa. Nessa ocasião, foi aplicado um questionário com o objetivo de apreender os conhecimentos dos/as docentes acerca dos livros voltados à infância com as temáticas do projeto.

Outra reunião foi realizada com os familiares das crianças, para serem informados sobre o trabalho e seus objetivos, para que o conhecessem e pudessem fazer eventuais questionamentos, além de autorizar a participação delas. As crianças também foram informadas sobre o projeto e assinaram, junto com os adultos, o termo de consentimento livre e esclarecido. Participaram dos encontros da pesquisa 48 crianças: 25 estudantes do 5०A (16 meninas e 9 meninos) e 23 do 5B (6 meninas e 17 meninos). A escolha das salas foi feita pela equipe de direção da escola, sob a alegação de apresentarem "problemas" relacionados à disciplina e à sexualidade.

1 Livros infantis trabalhados/mediados nos encontros: Menino brinca de boneca?, de Marcos Ribeiro; O menino Nito, de Sônia Rosa; Ceci tem pipi?, de Thierry Lenain; Entre explosões e cortes na barriga: as curiosidades de Rafael/Entre sementes e cegonhas: as curiosidades de Gabriela e A menina e o menino que brincavam de ser..., de Tina Xavier; $A$ princesa sabichona e o Principe Cinderelo, de Babette Cole; $O$ sapo que virou principe, de Jon Sciezka; Até as princesas soltam pum, de Ilan Brenman. 
Foram totalizadas 52 horas em 12 encontros semanais, em cada uma das turmas,e em um seminário final com todas as crianças. Em cada encontro temático, um livro e/ou vídeo ${ }^{2}$ de animação era utilizado para provocar discussões e apreender as representações das crianças e também para problematizar e mediar conceitos. No final dessa etapa do projeto, foi realizado um seminário com a apresentação e a estreia do filme de animação produzido pelo grupo.

Os resultados foram coletados com base nas produções das crianças e também, ao longo dos encontros, mediante anotações pessoais, uso de registro fotográfico e da gravação de algumas falas com o recurso de gravador. Também foi utilizado o recurso da filmagem, embora com pouco sucesso, em virtude de ruídos na sala. Ao final dos encontros, registravam-se as ações desenvolvidas em um diário de campo, que continha três partes: a descrição das atividades realizadas (com a transcrição das falas e atitudes das crianças); a narrativa dos sentimentos e opiniões de cada pesquisador $/ \mathrm{a}^{3}$ sobre o encontro e, ao final, um espaço para destacar aspectos importantes para os encontros subsequentes. As reuniões da equipe da pesquisa ocorriam semanalmente para (re)planejar e discutir os aspectos coletados e produzidos nos encontros.

Em cada encontro, reservava-se um momento para a produção escrita e/ou desenhada das crianças sobre o tema em discussão. Esse material tornou-se um elemento primordial para a pesquisa. Além disso, nesses momentos foram priorizadas as fotografias e sobretudo as falas, as formas de dizer, de como dizer, de se calar, de ocultar, os silêncios, os ditos e interditos. Sobre eles era problematizado o que Foucault (2003, p. 9) alerta sobre os procedimentos de exclusão e interdição no ato da fala: "Sabe-se bem que não se tem o direito de dizer tudo, que não se pode falar de tudo em qualquer circunstância, que qualquer um, enfim, não pode falar de qualquer coisa”. A produção da fala das crianças também sofre as interdições sociais relativas ao que se pode falar, quando e com quem. Era frequente ouvir crianças dizerem que não podiam pronunciar tais palavras, pois eram consideradas proibidas ou, como explicavam, "eram besteiras". Um caso emblemático foi o de um menino que levantava várias discussões e trazia perguntas para o grupo sobre os temas em foco. No entanto, após as discussões, ele continuava a indagar e a buscar um diálogo sobre o assunto com seus familiares, mas sem êxito. A mãe então disse que, se ele continuasse a falar naqueles "assuntos", ele seria retirado do projeto. $\mathrm{O}$ menino, porém, concordou em se calar em casa para dar continuidade à participação. Esse fato revela o procedimento da interdição da família na fala da criança. Na escola, por intermédio das ações da pesquisa, ele encontrou espaços de diálogo e de fala sobre assuntos que nem sempre tiveram espaço, condições e liberdade. No entanto, até mesmo nesse espaço, outras negociações são produzidas, pois nem sempre é pertinente dizer tudo, nem em qualquer

2 Filmes de animação trabalhados/mediados nos encontros: livro animado O menino Nito (Projeto A Cor da Cultura); Queméo bom?, Criança não trabalha, Disco Voador, Estatuto Animado I II (Direção Animare); RosaAzul no reino do arco-íris e Isso é de menina ou de menino? (Direção UFMS/Tina Xavier e Anima Escola); Eu queria ser um monstro (Direção Marão).

3 A equipe era composta por mim, como coordenadora da pesquisa, e voluntários/as, aos quais agradeço pela participação: Cristine Novaes Barbosa da Rocha; Telma Iara Bacarin; Suellen Oliveira Duarte Ramos Próspero; Ingrid Roque Pérez e Daniel Delmanto. Também contamos com a colaboração, nos primeiros encontros, de Sabrina Canepa Lameu. 
lugar. Nesse processo, há possibilidades de controle, seleção, organização, mas também de resistências e de novas possibilidades.

A vivência na pesquisa-ação com crianças trouxe para os pesquisadoras/es muitos desafios. Um deles foi a reflexão constante entre a imersão nas ações e o distanciamento necessário para analisar e discutir os aspectos coletados. A atividade de pesquisador/a nos incitava constantemente a questionar nossas práticas individuais e coletivas com o grupo de crianças; ao mesmo tempo, havia a preocupação em registrar os dados, instigar problematizações, dissensos, provocações, questionar nossa conduta e ação. Também era permanente o perigo do hermetismo por parte dos adultos e do enfado por parte das crianças, com discussões que para elas nada significavam ou não correspondiam aos seus interesses.

Muitas das inquietações no decorrer da pesquisa vêm suscitando, nas últimas décadas, reflexões em pesquisadoras/es que adotam perspectivas etnográficas e/ou de campo em seus estudos. A pesquisa aqui referida, além de problematizar aspectos relacionados ao envolvimento participativo, traz outro elemento, que é a utilização/vivência de pesquisas com crianças.

A investigação sobre a infância foi, durante várias décadas, influenciada por um viés adultocêntrico, pois tinha como referencial a pessoa adulta. $\mathrm{O}$ mesmo acontece com relação à produção de livros para a infância: os/as autores/as, em sua maioria, são adultos que escrevem para crianças. Essa é uma das questões que a pesquisa tenta discutir, problematizando livros e produzindo metodologias e artefatos culturais para e com crianças.

Oliveira-Formosinho (2008,p.72) destaca a importância de se escutar as vozes das crianças e assinala as responsabilidades teórico-metodológicas de se lidar com esse público:

$\mathrm{O}$ facto de a investigação ser realizada com criança e não sobre crianças representa várias responsabilidades e preocupações para o investigador, algumas análogas àquelas que caracterizam a investigação que recorre a métodos por procuração e algumas que representam uma novidade e são muito específicas à investigação baseada nas perspectivas das crianças. [...] De facto, a novidade e a complexidade desta abordagem recente não deverão representar uma barreira, mas antes um motor de investimento no sentido de a participação da criança ser plenamente reconhecida, o que, na nossa óptica, só deverá ser alcançado através da criação de oportunidades reais e efectivas.

A autora estimula a refletir sobre a potencialidade da pesquisa com crianças e não somente a pensar em pesquisa sobre elas. As pesquisas sobre e com crianças, inclusive com o objetivo de escutar suas vozes, compreender como constroem representações, teorias e hipóteses, entendem que estas são produtoras de cultura como sujeitos sociais e históricos. O desafio que se impõe é a busca por pressupostos metodológicos capazes de dialogar com esse público, visando à sua efetiva participação.

Gobbi (2002) confirma o que se vem constatando, ao ressaltar que historicamente a criança sempre foi objeto de estudos. Por vezes, ela foi (e em muitos casos ainda é) retratada pelos olhares e representações dos adultos. A autora assegura que os estudos produzidos pela pedagogia da educação infantil caminham no intuito de afirmar que a criança é criadora de cultura, sujeito de sua história. Instiga, por isso, a pensar em estratégias e pressupostos de pesquisa que visem dialogar com ela e coletar suas opiniões e representações. Os estudos da sociologia da infância também pretendem rever a infância 
como objeto sociológico, em detrimento da perspectiva biologicista, historicamente consolidada, como afirma Sarmento (2005).

A realização de pesquisas com crianças, observando-as, ouvindo-as, aprendendo com o que elas têm a dizer, problematiza e refuta a construção de uma infância essencializada e universal. No entanto, essas pesquisas podem cair na armadilha de buscar compreendê-las na produção de saberes-poderes com o objetivo de exercer sobre elas um poder de controle e vigilância.

Essas reflexões, questionamentos, ponderações, estiveram presentes na elaboração do projeto de pesquisa e, sobretudo, nos momentos coletivos com as crianças. A alternativa foi mais que uma simples coleta de representações. Optou-se por um processo que compreendia debates, mediação de conceitos, discussão sobre a produção de saberes-poderes na interação entre adultos e crianças. Por isso, a pesquisa-ação nos pareceu a perspectiva teórico-metodológica mais apropriada, razão por que foi adotada na investigação. Em momentos de oralidade, na produção de textos e desenhos, nos diálogos e produções de materiais educativos, cada frase das crianças foi valorizada e problematizada ao lidar com conflitos nos momentos de negociação (sobretudo nos momentos de produção de materiais); procurou-se, como propõe Louro (2007), valorizar o local e o particular e com eles trabalhar. Também foi adotada a prática de operar com a incerteza na construção de possibilidades de interlocução com as crianças e de nos colocar em xeque como participantes da pesquisa.

Costa (2002, p. 104) ressalta a importância da utilização da pesquisa-ação. Para ela, é uma estratégia de fabricação de discursos que, tanto quanto outras formas de produção de saber, visa ao controle e à regulamentação daquilo que narra. Para a autora, essa "vontade de saber" é também "vontade de poder":

Os objetos não existem, para nós, sem que antes tenham passado pela significação. A significação é um processo social de conhecimento. Quando indivíduos, grupos, tradições, descrevem ou explicam algo em uma narrativa ou discurso, temos a linguagem produzindo uma "realidade", instituindo algo como existente de tal ou qual forma. Assim, quem tem o poder de narrar pessoas, coisas ou processos, expondo como estão constituídos, como funcionam, que atributos possuem, é quem dá as cartas da representação, ou seja, é quem estabelece o que tem ou não tem estatuto de "realidade".

Costa adota a perspectiva dos estudos pós-estruturalistas, dos estudos culturais e dos estudos feministas, para os quais a linguagem, o discurso e a representação são elementos que merecem ser pesquisados. Ela ressalta:

Pesquisar é uma atividade que corresponde a um desejo de produzir saber, conhecimentos, e quem conhece, governa. Conhecer não é descobrir algo que existe de uma determinada forma em um determinado lugar do real. Conhecer é descrever, nomear, relatar, desde uma posição que é temporal, espacial e hierárquica. O que chamamos de "realidade" é o resultado desse processo. A realidade ou "as realidades" são, assim, construídas, produzidas na e pela linguagem. Isto não quer dizer que não existe um mundo fora da linguagem, mas sim, que o acesso a este mundo se dá pela significação mediada pela linguagem. (idem, p. 107) 
A pesquisa-ação, ao propiciar aos sujeitos condições de produzir discursos sobre sua vida, sobre os efeitos que eles são capazes de produzir em sua constituição identitária, por exemplo, é uma abordagem que promove o debate e a reflexão sobre a produção de "verdades" e vontades de saber e de poder. Em cada um dos encontros com as crianças, foi possível observar e propiciar momentos de diálogo, problematização dos temas da pesquisa e provocar novas formas de pensar sobre o que historicamente era admitido como natural, como a construção da masculinidade/feminilidade hegemônica, da heterossexualidade compulsória, das várias possibilidades de ser e de se constituir relativamente à própria identidade.

Ao longo dos 12 encontros com cada um dos grupos, foi possível vivenciar vários dos aspectos aqui descritos. O maior desafio foi o de aprender junto e o de colocar cada participante adulto, juntamente com as crianças, no terreno das incertezas e da eterna dúvida; de refletir sobre os processos que nos constituem como sujeitos na contemporaneidade e, sobretudo, como destaca Costa (idem, p. 99), de aceitar que um pouco da história e das representações das crianças (pelo menos as produzidas naquele momento!) pudesse ser narrado coletivamente, ressaltando uma das características fecundas da pesquisa-ação com crianças, que é a de "produzir narrativas, saberes, discursos que instituem identidades".

A seguir, serão analisados os aspectos referentes a uma das atividades desenvolvidas no terceiro encontro da pesquisa e as representações das crianças produzidas/discutidas.

Antes, no primeiro encontro, havíamos realizado a dinâmica das apresentações pessoais e as do projeto, seguidas da coleta das dúvidas e curiosidades das crianças com a elaboração do autorretrato e de uma narrativa biográfica. Nessa escrita, as crianças foram convidadas a falar sobre o que consideravam ser menino ou menina.

No segundo encontro, foram apreciados e discutidos textos e desenhos produzidos no encontro anterior, para aí prosseguir a discussão. As perguntas individuais foram transformadas em dúvidas coletivas; temas comuns a serem abordados e conversados nos encontros e em questões/produções, sobre o que é ser menino ou menina, que ganharam tônica nas discussões. As crianças foram estimuladas a pensar sobre a construção social das diferenças de gênero. O livro adotado para provocar os questionamentos foi Menino brinca de boneca?, de Marcos Ribeiro.

No terceiro encontro, seguiu-se a mesma dinâmica do encontro anterior e deu-se continuidade à leitura com o livro infantil A menina e o menino que brincavam de ser..., de Tina Xavier. O livro conta a história de uma menina, Ana Carolina, que, de tanto ganhar objetos cor-de-rosa, de viver em um mundo cor-de-rosa, convencionalmente destinado ao gênero feminino, um dia tornou-se uma menina rosa. $\mathrm{O}$ mesmo ocorreu com o menino Mateus, que, de tanto viver em um mundo azul, tornou-se um menino azul. O livro - que tem as crianças como protagonistas de suas próprias histórias, pois são elas quem encontram como sair dessas subjetividades ou como lhes resistir - problematiza essas construções identitárias de gênero até as crianças voltarem às suas cores de origem.

\section{ROSA E AZUL: MARCADORES SOCIAIS DE GÊNERO EM DISCUSSÃO}

A dinâmica utilizada para a leitura do livro $A$ menina e o menino que brincavam de ser... foi a da contação da história em duas etapas. A primeira ia até o momento em que os personagens se tornavam cor-de-rosa e azul. A partir daí, as crianças foram incentivadas 
a produzir um final para a história em forma de texto escrito e ilustrado. Um aspecto para ser aqui destacado foi o envolvimento das turmas no momento da contação da história e da produção dos textos. As imagens do livro eram exibidas à medida que a história ia sendo contada. Entremeados com a narração, vários comentários foram realizados pelas crianças. Um menino perguntou se realmente existiu uma menina que se tornara cor-de-rosa, demonstrando o jogo simbólico construído por ele. Tal aspecto, destacado por Sarmento (2005), leva a pensar sobre a possibilidade que esta criança tem em transitar entre o real e o imaginário e, com isso, produzir narrativas da cultura da infância.

No momento da exibição do corpo nu da menina e do menino no livro, vários risos ocorreram. Uma aluna disse que um menino e uma menina não podiam ficar nus, um na frente do outro; outra reforçou a imagem da menina que tinha o cabelo despenteado e crespo e que isso a tornava feia. Outra polêmica foi a da utilização do termo "vulva" e dos apelidos a essa parte do corpo feminino. O mesmo aconteceu com a palavra "pênis" e seus cognatos. Em vários momentos, perceberam-se comentários de crianças que demonstravam identificar-se com os personagens da história, especialmente em relação a alguns hábitos alimentares. A menina comia chipa ${ }^{4} \mathrm{e}$ tomava tereré, ${ }^{5} \mathrm{e}$ o menino comia sopa paraguaia; ${ }^{6}$ iguarias da culinária sul-mato-grossense.

A segunda etapa ficou com a exibição e discussão dos textos das crianças e a leitura e análise da segunda parte do livro, na qual se conta como a menina e o menino encontravam a solução para voltar às cores de origem.

Participaram desse encontro da pesquisa, nas duas salas, 24 meninos e 20 meninas. Portanto, os "achados" aqui descritos incorporam as 44 participações na produção do final da história.

Observaram-se, nessas participações, vários elementos que dizem respeito à construção de gênero. Em várias delas, é possível evidenciar aspectos referentes às representações hegemônicas de ser menino e ser menina; em outras, também foi possível observar mudanças discursivas com relação à problematização das normas sociais que produzem subjetividades.

Nas histórias produzidas pelas crianças para a resolução do conflito do livro, ou seja, sobre como a menina e o menino deixariam de ser respectivamente rosa e azul, foram observadas as atitudes tomadas pelos protagonistas, as formas de resolução/manutenção da problemática vivida, as questões pessoais e sociais. Para fins de análise, tentou-se agrupar os caminhos trilhados, observando as recorrências e dissonâncias nas narrativas. Cinco apontamentos se destacaram nas produções referentes ao final da história, que foram assim agrupados:

a | sete delas são de caráter conformista com a situação;

b| duas explicam a passividade dos personagens com o esquecimento ou a inércia diante da problemática vivida;

4 Chipa é um salgado de queijo de origem paraguaia. É feita à base de polvilho e queijo.

5 Tereré é uma bebida feita com a infusão da erva-mate, comumente consumida com água gelada e que se toma com bombilha.

6 Sopa paraguaia é um bolo de milho salgado muito consumido em Mato Grosso do Sul. Além do milho ralado, ingredientes como leite, óleo, queijo em abundância e cebola o tornam um prato delicioso. 
c| cinco, sobre o processo de mudança da menina e do menino como decorrência de intervenções externas em virtude das forças da natureza;

d| oito produções também propuseram a resolução do conflito com banhos e aparatos externos para eliminar o problema;

e | por fim, a maioria das produções (22) foi analisada observando mudanças pessoais e sociais dos personagens.

A partir da separação das narrativas nos blocos citados, foi preciso mais uma vez reagrupá-los, agora em três eixos de análise:

a conformismo e inércia dos personagens;

b| mudanças externas dos sujeitos; e

c| mudanças e possibilidade de resistência diante das imposições sociais de gênero.

Cada um desses apontamentos, retirado das narrativas, será destacado e problematizado teoricamente a seguir.

Os textos e ilustrações das crianças analisados sob a perspectiva de conformismo elou de esquecimento/inércia dos personagens diante da problemática vivida revelam atitudes de passividade diante das marcas e pedagogias de gênero. Eis alguns textos:

Quando os dois foram falar com as pessoas, elas estranharam, mas eles queriam ficar cada um com a sua cor. A Ana gostava muito da cor rosa, ela tinha todo o quarto dela rosa. E o Mateus tinha o quarto todo azul. Não fazia nenhuma diferença. Mas os dois viveram muito felizes porque eram as cores que eles sempre queriam. Mas a Ana falou para os pais dela que ela queria tudo rosa. E o Mateus falou para o pai dele que ele queria um carro todo azul. Os dois não ligavam para o que as outras pessoas falavam. Mas eles não se importavam. O que importa é que eles viveram felizes para sempre. (Menina, 15 anos, 5B).

Depois que os colegas perceberam, eles racharam de rir. Eles nem ligaram pra isso, a menina continuou rosa e o menino também o azul. (Menina, 11 anos, $5^{\circ} \mathrm{A}$ )

Ele resolveu tomar banho. Mas não adiantou nada. Ele viu que não tinha jeito e parou de tomar banho. Ele ficou tão bravo e foi dormir. Ao acordar, viu que não tinha jeito e teve que acostumar com aquilo. E ele conseguiu se acostumar. (Menino, 13 anos, 5 B)

Ana Carolina disse: “- Já sei. Vou conhecer o azul”. Só que ela via tudo rosa. Ela pensou e disse que iria tentar parar de pensar no rosa e foi assim. Já o Mateus resolveu pensar em outra cor diferente. Pensou no rosa e a Ana pensou no azul. E o Mateus foi ficar com o azul. (Menina, 10 anos, $5^{\circ} \mathrm{A}$ )

Cinco meninas e dois meninos produziram textos cujas representações demonstraram o conformismo às normas hegemônicas de gênero e/ou sua aceitação. No primeiro texto, os personagens centrais do livro - Ana Carolina e Mateus - conformaram-se totalmente a essas normas. Segundo a aluna, os personagens viverão felizes para sempre 
à medida que se conformarem com as regras e normas sociais vigentes e socialmente naturalizadas. $\mathrm{O}$ mesmo aconteceu no segundo texto, de uma aluna do $5^{\circ} \mathrm{A}$. A menina continuou rosa e o menino, azul. No terceiro texto, houve uma tentativa de mudança impetrada pelo menino. Ele tentou livrar-se das marcas de gênero e, sem sucesso, resolveu se "acostumar com aquilo". O que é mais desconcertante na frase é o veredito final: "e ele conseguiu se acostumar". O último texto também expressou a dificuldade dos meninos em romper com essas normatizações.

A seguir, podemos observar outros relatos da aceitação das normas vigentes:

Somente as cores rosa e azul são bonitas. Menina tem que usar só rosa mesmo. (Menina, 10 anos, $5^{\circ} \mathrm{A}$ ) (Diário de campo)

É porque o povo fala que a menina tem que usar rosa e o menino tem que usar azul, mas cada um pode usar a cor que ele quiser. (Pesquisador: Por que eles continuam rosa e azul? Referindo-se à ilustração). Porque ele não quer mudar de cor, nem ela. [Por quê?]. Porque ela gosta desta cor e ele também. (Você acha que estão felizes?). $\mathrm{Eu}$ acho. É que ele continuou usando azul e ela continuou usando rosa (Menina, 11 anos, $5^{\circ} \mathrm{A}$ ) (Diário de campo)

A afirmação de que a menina tem de usar o rosa e o menino o azul extrapola a questão ligada ao gosto pessoal por cores. Essa questão é eminentemente social, pois se aprende, desde muito cedo e no decorrer da vida, que essas cores identificam os meninos e as meninas. Essas cores produzem marcas identitárias, não permitindo pensar em outras formas de se fazer homem e de se fazer mulher. Ao contrário, demarcam a única forma legítima de ser masculino e de ser feminino.

O conceito de gênero é primordial para entender os elementos desses textos. Por gênero, entende-se:

a construção social feita sobre diferenças sexuais. Gênero refere-se, portanto, ao modo como as chamadas "diferenças sexuais" são representadas ou valorizadas; refere-se àquilo que se diz ou se pensa sobre tais diferenças, no âmbito de uma dada sociedade, num determinado grupo, em determinado contexto. (Louro, 2000, p. 26)

As formas de constituir-se masculino ou feminino são demarcadas e construídas socialmente. As cores rosa e azul tornaram-se marcas identitárias que definem um ideal de masculinidade e feminilidade. Os textos das crianças/adolescentes analisados nessa perspectiva confirmaram que o menino deve usar o azul e acostumar-se com ele, e a menina, com a cor rosa. As cores marcam os corpos - o masculino e o feminino -, ditando regras e prescrições normativas de como se constituir, se portar, se movimentar, de como agir e de como ser na vivência e na constituição da identidade de gênero e também da identidade sexual.

Observou-se, nos textos, um controle social mais pronunciado nas falas e nas condutas dos meninos. Eles são mais vigiados e regulados para serem "homens de verdade", denotando que as questões gênero e identidade de gênero estão profundamente marcadas pela identidade sexual. Isso evidencia que a questão de gênero envolve o corpo, indicando, sobretudo, corpos sexuados. 
Outro elemento presente nos textos é a promoção do enlace matrimonial dos dois personagens do livro. As crianças foram enfáticas em dizer que a menina e o menino da história, quando crescessem, iriam casar-se e ter filhos/as:

Eles se conheceram e contaram as suas histórias um para o outro. Ficaram felizes de ser diferentes dos outros amigos. Foram para a escola juntos e aí começaram a namorar e se casaram. Tiveram uma filha rosa e foram felizes para sempre. Foram embora para casa em outra cidade. (Menina, 12 anos, $5^{\circ} \mathrm{A}$ )

Eles foram para escola e se conheceram. Tornaram-se grandes amigos. Eles conversaram como foi a vida desde pequenos. Eles eram tristes, mas conheceram outras cores. Antes de voltar ao normal, eles passaram por várias outras cores. $\mathrm{Na}$ adolescência, começaram a namorar e se casaram e tiveram três filhos. Viajaram para todo lugar possível até para a Disney. (Menina, 10 anos, $5^{\circ} \mathrm{A}$ )

$\mathrm{O}$ casamento dos personagens foi amplamente citado nos textos. Na primeira citação, a imposição das regras da construção de gênero se perpetua com o nascimento da "filha rosa" do casal. Na outra, a menina enfatiza que, antes de voltarem ao "normal", eles passaram por várias cores; depois se enamoraram, casaram-se e tiveram filhos. Nas falas das crianças, aceitar que o menino pudesse ser o melhor amigo da menina, e vice-versa, provocou desconforto. Para tornar essa amizade aceitável, elaboraram finais felizes para o casal. A ideia de amor romântico, com final feliz, visando à completude das pessoas, está presente nesses enunciados. Outra questão é novamente a prescrição da heterossexualidade compulsória e do estabelecimento da norma.

A heterossexualidade é um modelo socialmente considerado padrão. Isso afeta a constituição da subjetividade. Britzman se vale do conceito de heteronormatividade para explicar a "obsessão com a sexualidade normalizante, através de discursos que descrevem a situação homossexual como desviante"(1996, p. 79).

Os textos desse agrupamento, produzidos pelas crianças, além de retratar a conformidade e a aceitação das imposições sociais de gênero, evidenciaram que os meninos são mais regulados que as meninas. Uma explicação possível para esse fato é de que socialmente se estabelece uma relação linear entre gênero-sexualidade-desejo. $O$ menino será constituído como do gênero masculino e será necessariamente heterossexual. $\mathrm{O}$ mesmo ocorre para a menina que, dentro dessa norma heteronormativa, será inequivocamente do gênero feminino e heterossexual. $\mathrm{Na}$ pesquisa em questão, essas imposições sociais que constroem práticas e educações para garantir a heterossexualidade como a única forma de identidade sexual pareceu afetar mais os meninos que as meninas, justamente pelo medo de serem taxados como potencialmente homossexuais.

Outros textos apontaram resolução dos conflitos vividos por Ana Carolina e Mateus. Cinco textos, escritos por quatro meninos e uma menina, ressaltaram que haveria uma mudança de fora para dentro à medida que se transformassem por osmose ou ao conhecerem fenômenos da natureza, como o arco-íris.

Ana Carolina conheceu Matheus e eles falaram o que aconteceu. Eles viram o arco-íris e pegaram nas mãos e as cores se misturaram e desbotou. Voltaram a sua vida porque viram como o arco-íris e as outras cores eram bonitas e tudo voltou ao normal. (Menino, 11 anos, $5 \circ$ B) 
Os dois começaram a ficar rosa e azul. Mas isso foi só no final. Eles começaram a conhecer cores novas, cores do arco-íris. E assim viveram felizes para sempre. (Menina, 12 anos, $5^{\circ} \mathrm{A}$ )

Os textos revelaram, de parte das crianças, certa passividade, pois elas são "salvas" por um acaso/fenômeno da natureza. Essa representação pode fazer pensar na constituição identitária como construção natural ou essencializada dos sujeitos. O conceito de identidade, na perspectiva dos estudos culturais e pós-estruturalistas, é uma atribuição cultural. Nesse sentido, "identidade não é uma essência; não é um dado ou um fato - seja da natureza, seja da cultura. A identidade não é fixa, estável, coerente, unificada, permanente. A identidade tampouco é homogênea, definitiva, acabada, idêntica, transcendental"'Silva, 2003, p. 96). O que se observa nos textos das crianças, destacados no agrupamento em análise, é uma ideia prevalente na sociedade de que há uma preponderância da influência social na construção dos sujeitos. Isso também se tornou explícito nos textos produzidos (cinco meninos e três meninas), em que o "banho" é a solução para a problemática das cores rosa e azul no corpo das crianças.

No final da história, o Matheus muda de cor e fica a cor normal de sempre. Ele tomou um banho de chuveiro e saiu a cor azul. A mesma coisa fez a menina, ela também mudou de cor e ficou a cor normal de sempre. Ela tomou um banho de chuveiro e saiu a cor rosa. (Menino, 10 anos, $5^{\circ} \mathrm{B}$ )

Depois de uns dias, todos ficaram percebendo o que estava acontecendo com os dois. A mãe da menina a levou ao médico para ver o que estava acontecendo. A mãe do menino também o levou ao médico. O médico deu um banho neles dois e saiu a mancha rosa e azul. (Menina, 10 anos, $5^{\circ} \mathrm{A}$ )

Eles resolveram viajar para Bonito porque ouviram falar que lá tem águas milagrosas. E no outro dia eles acordaram e se olharam no espelho: - Viva! Disseram. Estamos livres do rosa e do azul. Vamos conhecer outras cores e voltar as nossas cores normais. (Menina, 10 anos, $\left.5^{\circ} \mathrm{A}\right)$

A resolução do conflito elaborada por algumas das crianças foi a do banho. Ele pode ser de chuveiro, de rio, de cachoeira, de bacia (muitos propuseram que as crianças ficassem de molho!) ou mesmo nas águas milagrosas de um rio. A ideia preponderante é de que essas cores possam ser retiradas e que elas não deixariam marcas identitárias. Uma das meninas propõe que as crianças sejam levadas a um médico para se curarem. Essa representação é significativa pelo argumento da matriz biológica para devolver a normalidade aos sujeitos. A autoridade do discurso médico é socialmente legitimada pelas redes de poder, que lhe permitem falar da sexualidade e do gênero "normal". O termo "normal" também é constantemente reforçado nas narrativas. Voltar ao "normal" dos personagens pode indicar o que Silva propõe: que a "identidade normal é 'natural', desejável, única" (idem, p. 83).

A maioria dos textos (22 - 10 meninas e 12 meninos) trouxe enunciados que revelaram mudanças e resistências às imposições de gênero. Neles se observa a participação ativa dos personagens para questionar as normas e produzir outras subjetividades. Há textos em que os personagens exigem que se comprem objetos de cores diversas; em 
outros, há questionamentos sobre as separações de gênero; há formas de resistência na negação de se conduzir diante do que é considerado idealização de masculino e feminino:

Os dois ficaram muito felizes porque cada pessoa pode usar qualquer cor. Menino pode usar rosa e menina pode usar azul. Eles andavam para todos os lados e encontravam cores: rosa, azul, amarela, vermelha. (Menina, 10 anos, $5^{\circ} \mathrm{A}$ )

Eles diziam que era natural porque azul era de menino e rosa de menina. Os pais não notaram porque eles nasceram azul e rosa. Aí que eles conheceram isso tudo. Quando se conheceram e ficaram amigos, viajaram para Bonito. Nadaram com os peixes. Quando eles cresceram, viraram namorados, noivos e casaram-se. Tiveram um filho chamado Gabriel que não foi apresentado a um mundo azul. Alguns anos depois tiveram uma filha chamada Andreza que não viveu em um mundo rosa. (Menino, 10 anos, $5^{\circ} \mathrm{A}$ )

Mateus ficou azul mas ele fez uma promessa para ele mesmo que nunca mais ia ganhar coisas azuis, só coisa branca. Para voltar a ser normal como era antes. A menina fez a mesma coisa. (Menino, 11 anos, $5^{\circ} \mathrm{B}$ )

No final a menina acordou rosa e o menino acordou azul. A menina brinca de carrinho e o menino brinca de boneca. Ela comprou nas casas Bahia uma cama de "carros" e ele também comprou a cama rosa da Barbie. (Menino, 12 anos, $5^{\circ} \mathrm{B}$ )

Os textos das crianças apontam para novas construções das identidades de gênero. A possibilidade de usar qualquer cor permite pensar nas multiplicidades de formas de ser menino e menina. Em vários textos, aponta-se a construção de um mundo plural e colorido. Em um deles, os personagens, quando adultos, não apresentarão aos seus filhos e filhas o "mundo azul e rosa" em que estiveram imersos. A última das narrativas citadas indicou a possibilidade de ação e resistência que as crianças têm em optar por novos brinquedos e artefatos culturais.

As narrativas que foram analisadas nesse último agrupamento, o das resistências e de novas possibilidades de se constituir meninos e meninas, indicaram mudanças nas representações de gênero em relação às que tinham no início dos encontros da pesquisa-ação. Nesse aspecto, observa-se a fertilidade desses momentos com o intenso propósito de reflexão e problematização dos discursos hegemônicos de gênero.

Nos textos das crianças, as possibilidades de ser masculino e feminino são enfocadas sob a perspectiva dos papéis de gênero e não necessariamente em relação ao processo de constituição identitária de gênero. Esse elemento, presente nas narrativas, é comumente encontrado em várias narrativas de pessoas adultas (e também em vários estudos), como alerta Louro (1997). Para a autora, analisar essa problemática valendo-se dos papéis de gênero remete a questões de cunho pessoal. O desejável seria analisá-la como constituinte da identidade dos sujeitos. Não se almejava, evidentemente, que as crianças consolidassem em seus textos essas questões teóricas e esse nível de elaboração. $\mathrm{O}$ que se pretende analisar é o processo pelo qual elas atribuem sentidos pessoais aos sujeitos masculinos e femininos. Essas representações não são pensadas como aspectos mais abrangentes, e sim como atribuições de cunho exclusivamente pessoal. Por isso, 
tentamos provocar discussões sobre os aspectos sociais que nos indicam certos modelos de ser menina e de ser menino. Perguntamos: Por que estas regras foram impostas? Quem as produziu? Todas as meninas são assim? Agem de forma igual? E os meninos? Que outras maneiras há de ser menina e de ser menino? De que maneira se poderá desconstruir o modelo único? Entre outras tantas questões suscitadas nos encontros.

Essas e outras tantas questões foram levantadas no decorrer dos encontros da pesquisa-ação. Num dos encontros, um menino colocou as duas mãos na cabeça, balançando-a e cerrando os olhos com força, dizendo: "não aguento mais pensar; minha cabeça está fervendo. Não sai mais nada”. Esse episódio foi emblemático para refletir, conjuntamente, que nem sempre pensamos sobre o que é dado socialmente como natural. Essas regras e normas não são pensadas nem provocam estranheza. Elas existem e pronto! Quando vistas como produções, como representações sobre algo, e constatado que são sempre construídas, elas poderão ser questionadas, e nós, instigados/as a pensar e a construir outras representações às que nos foram impostas.

O conceito de representação aqui adotado não é o de uma abstração mental ou de alguma interioridade psicológica, mas uma forma de atribuição de sentido (Silva,2003). O autor concebe o conceito como sistema de significados, atribuição de sentidos, traduzido por termos como inscrição, marca, traço, significação, face material, visível, palpável do conhecimento (idem, p. 91). É nessa perspectiva que se tentou analisar coletivamente os textos e as falas das crianças. Elas compartilham de conceitos, teorias, ideias, proposições partilhadas e socialmente produzidas; ainda, interagem e produzem representações à medida que tomam consciência de que são seres sociais que podem questionar, aceitar, rejeitar, enfim, atuar nessas teias da linguagem e, sobretudo, tentar estratégias de fugas e resistências.

Os textos das crianças que apresentam representações de gênero com outras maneiras de ser menino ou menina admitem mudanças com aproximação de fronteiras do que é considerado de um gênero em detrimento do outro. Por exemplo, dizem que menino pode brincar com boneca "de menina"; que menina pode praticar esporte "de menino". Essas questões, ao mesmo tempo em que indicam a possibilidade de atravessamentos das fronteiras, também delimitam o que é de conduta e de domínio de um gênero e de outro. Também demonstram os parâmetros de normalidade na medida em que a sociedade fixa uma identidade como norma.

As produções das crianças foram problematizadas nos encontros seguintes. Refletiu-se sobre vários dos aspectos aqui destacados. Outras formas de pensar a construção identitária dos personagens foram reelaboradas no roteiro coletivo de um filme de animação, tema do próximo tópico.

\section{PRODUÇÃO COLETIVA DE FILME DE ANIMAÇÃO}

No decorrer dos encontros, quando se apresentaram as produções textuais e ilustrativas das crianças, em especial do livro infantil do qual se extraíram os relatos analisados no item anterior, sugeriu-se construir coletivamente um roteiro de filme de animação. Vários elementos, que já haviam sido apontados, foram novamente retomados, assim como foram pensadas outras possibilidades de finalização da história dos personagens do livro. Além do filme, como produto final da pesquisa, também foi pensada a 
construção de uma personagem, a princesa pantaneira, que será protagonista de um livro infantil e de um filme de animação. ${ }^{7}$ Portanto, ao concluirmos a pesquisa, no segundo eixo teórico-metodológico da pesquisa-ação com crianças, teremos produzidos dois filmes de animação e um livro para a infância. Todos os produtos foram criados juntamente com as crianças ou tomando-se por base elementos coletados com/para esse público.

A seguir, será relatado o processo de produção do filme, que fora elaborado em 2010 em decorrência das atividades descritas e analisadas no item anterior.

Inicialmente, indagou-se das crianças/adolescentes o que gostariam de expressar no filme. Em seguida, foram instigadas a pensar sobre a construção dos personagens no contexto em que viviam, em suas vivências e experiências, inclusive na escola. Aproveitaram-se vários elementos por elas trazidos e construídos nos textos; outros, rejeitados. Na construção dos personagens, Ana Carolina passou a se chamar Jéssica e o Mateus, Júnior. Vários filmes de animação produzidos com a participação de crianças e jovens foram exibidos e analisados pelo grupo. Algumas técnicas de produção cinematográfica foram trabalhadas nos encontros, enfatizando algumas das linguagens do cinema de animação. As duas salas participaram da construção coletiva. Enquanto uma turma iniciava a escrita de uma cena, a outra the dava continuidade. A construção final do roteiro e da criação dos desenhos foi feita em parceria com uma produtora de filmes de animação para a produção e pós-produção. As crianças e a equipe da pesquisa participaram do processo de pré-produção e produção, com sugestões para a finalização do filme. A proposta da elaboração coletiva era de que as crianças fossem protagonistas dessa ação. Por esse motivo, o filme foi produzido em meio a negociações, em especial entre interesses das crianças e dos adultos.

O filme conta a história da Jéssica e do Júnior no mundo das cores. ${ }^{8}$ Ele e ela, tal como o livro, tornam-se seres cor-de-rosa e azul. Conhecem-se na escola. Dão-se conta que a escola também produz diferenças e desigualdades de gênero. Resolvem encontrar soluções e pistas para mudar a situação que os aflige. Questionam o porquê de as regras serem impositivas na construção de meninos e meninas. À medida que questionam, promovem novas formas de ser. Essas novas possibilidades não estão fora das relações de poder; no entanto, promovem outras possibilidades menos prescritivas e mais plurais.

7 A produção do livro e do filme de animação, intitulados A princesa pantaneira, ocorreu entre os meses de outubro e dezembro de 2011, com novas turmas de crianças (também estudantes do $5^{\circ}$ ano do ensino fundamental) e com a participação de algumas que haviam participado dos encontros da pesquisa-ação no ano anterior. Para a produção do filme, optamos por realizar oficinas de trabalho específicas para a construção do roteiro coletivo, criação de cenários e personagens, diálogos, filmagens e planejamento da pós- produção do filme. O livro e o filme trazem como personagem principal uma princesa diferente da dos contos de fadas tradicionais, justamente para desconstruir o modelo único de ser menina/mulher. Ver: A princesa pantaneira. Produção Universidade Federal de Mato Grosso do Sul, Tina Xavier e GEPSEX. Direção de Constantina Xavier Filha (Tina Xavier). Campo Grande, MS: UFMS/Animare, 2012. DVD (9 min.), son., color.

8 O filme foi realizado em parceria com o Instituto Animare (MG). Ver: Jéssica e Júnior no mundo das cores. Produção Universidade Federal de Mato Grosso do Sul e Animare. Direção-geral de Constantina Xavier Filha (Tina Xavier). Direção artística de Marcelo Branco. Campo Grande, MS: UFMS/Animare, 2009.DVD (3 min. 44 seg.), son., color. Disponível em: <http://www.youtube.com/watch?v=9A3fevTe4ZY>. Acesso em: 9 ago. 2011. 
A produção do filme também propiciou a coleta de dados e, sobretudo, a possibilidade de pensar coletivamente os artefatos culturais voltados à infância, além de vários conceitos e representações de gênero e de sexualidade das personagens. $\mathrm{Na}$ maioria dos casos, as crianças são alijadas desse processo de produção, como também não são induzidas a pensar sobre ele.

A opção pela produção dos filmes de animação ocorreu no decorrer da pesquisa. Anteriormente, foi planejada unicamente a produção do livro com a participação efetiva das crianças. No entanto, percebeu-se que a leitura de livros é considerada enfadonha para muitas crianças. Algumas diziam não gostar de "ler letrinhas", somente das ilustrações. Alguns livros que tinham poucas ilustrações foram refutados por muitas delas. Outras tentavam e conseguiam ler, mas não conseguiam apreender as ideias expressas no texto. Várias estratégias foram utilizadas, entre elas, a leitura coletiva, já que não se tinha a pretensão nem o objetivo de trabalhar especificamente a produção de texto e as estratégias de leitura (apesar de o projeto passar transversalmente por essas questões!). A estratégia foi trazer livros combinados com filmes de animação; vários deles, inclusive, produzidos por crianças. Logo após a exibição dos vídeos, era perguntado sobre os conceitos neles veiculados e todas as crianças conseguiam expressar-se com riqueza de detalhes, algo que muitas crianças não conseguiam após a leitura dos livros. Esse aspecto fez pensar-se sobre os impasses e desafios impostos à escola na contemporaneidade, em que as crianças crescem em meio a culturas visuais. Nessa forma de ser e estar no mundo, em que elas estão se constituindo, a atenção se torna difusa e fugaz. Para lidar com essas questões, além de utilizar filmes e sua produção, foram planejadas inúmeras dinâmicas e estratégias para garantir a atenção e participação das crianças. Eis outro desafio importante para a utilização e vivência de pesquisa-ação com esse público.

O filme foi uma ação bem-sucedida na produção coletiva de um artefato cultural que teve como objetivo questionar o processo de constituição da identidade de gênero. $\mathrm{Na}$ construção do roteiro e das personagens, foi perguntado como seriam e como poderiam ser as diferentes formas e jeitos de ser menina e menino. Esse processo foi caracterizado por negociações entre o que se pretendia contar e os "modos de endereçamento" que eram pensados ser o público a atingir.

A seguir, na última parte deste artigo, serão referidas, para efeito de síntese, algumas discussões teóricas acerca dos "achados" da pesquisa, buscando provocar problematizações sobre as representações que as crianças produzem e são produzidas nesse processo.

\section{PROBLEMATIZANDO AS REPRESENTAÇÕES DE GÊNERO E SEXUALIDADE DAS CRIANÇAS}

As representações de gênero e sexualidade apreendidas, socializadas, problematizadas, tensionadas... os encontros da pesquisa-ação com as crianças levantaram muitos questionamentos teóricos e provocaram reflexões sobre as construções de identidade.

As representações são atribuições de sentidos produzidas socialmente. Para que algumas delas se tornem hegemônicas, há vários investimentos de poder que as legitimam 
como "verdade". Nesse processo, os sujeitos interagem, produzem, apropriam-se, resistem às várias representações para constituir sua identidade.

As ações da pesquisa-ação com as crianças mostraram-se férteis para se conhecer as representações que produzem e que as constituem como sujeitos, além de promover momentos de reflexão sobre assuntos naturalmente aceitos e pouco discutidos na escola. E aqui vale retomar o já citado por Costa (2002), quando sintetiza a importância dessa perspectiva de pesquisa, afirmando que pesquisar corresponde ao desejo de produzir saber, como já referenciado anteriormente.

Pesquisar com crianças foi sobretudo aprender junto; foi propiciar e provocar os participantes, adultos e crianças, a rever questionamentos, a levantar novos questionamentos sobre temas e pontos até então silenciados e pretensamente indiscutíveis. Pesquisar e produzir para/com crianças também foi um desafio que colocou em xeque o grupo de pesquisadores/as, por perturbar ou abalar a solidez de suas certezas.

No decorrer da pesquisa, o grupo se deparou com crianças ávidas por discutir assuntos que diziam respeito à sua vida. Aos poucos, o grupo foi instigado a pensar numa afirmação de Louro (2000, p. 61): "A sexualidade não é apenas uma questão pessoal, mas é social e política"; e: "A sexualidade é aprendida, ou melhor, é construída, ao longo de toda a vida, de muitos modos e por todos os sujeitos".

As crianças e os adolescentes, sujeitos da investigação, narraram situações cotidianas e vivências pessoais que expressavam questões de gênero e de sexualidade. Essas questões, apesar de afetar algumas pessoas, extrapolavam as questões de ordem pessoal. São eminentemente sociais e históricas. São determinadas por discursos que regulam, normatizam e impõem verdades sobre os sujeitos. Tencionar esses vários discursos que nos impelem a ser de determinado jeito foi um objetivo constantemente perseguido nas inúmeras atividades da pesquisa-ação com as crianças.

A sexualidade, segundo Foucault, é um dispositivo histórico, ou seja, uma invenção social. Segundo ele:

A sexualidade é o nome que se pode dar a um dispositivo histórico: não à realidade subterrânea que se apreende com dificuldade, mas à grande rede de superfície em que a estimulação dos corpos, a intensificação dos prazeres, a incitação ao discurso, a formação dos conhecimentos, o reforço dos controles e das resistências, encadeiam-se uns aos outros, segundo algumas grandes estratégias de saber e de poder. (1997, p. 100)

É no âmbito da cultura, por intermédio das inúmeras estratégias de saber-poder, que os sujeitos vivem sua sexualidade e se constituem identitariamente. Conforme Foucault, esse processo se dá em meio a relações de poder, que possibilitam formas de resistência.

A inscrição do gênero no corpo - masculino ou feminino - é também um processo decorrente do contexto de determinada cultura. Segundo Scott, "o gênero é um elemento constitutivo de relações sociais com base nas diferenças percebidas entre os sexos" (1995, p. 86). A diferença biológica é socialmente ressignificada. Na perspectiva desta autora, portanto, discutir gênero é essencialmente colocá-lo nas relações sociais. É na sociedade, nas relações entre as pessoas, que o gênero é criado e estabelecido. É 
no ambiente social que os sujeitos se fazem homens e mulheres, em um processo continuado e dinâmico, não dado no nascimento e a partir daí marcado para sempre. Os seres humanos vão construindo ativamente a sua identidade de acordo com as inúmeras influências sociais - como a da educação, no que se refere à sexualidade e gênero - com as quais têm possibilidades de interagir. Esse processo identitário não é determinista ou passivo; faz-se com lutas, conflitos e negociações entre aspectos de ordem pessoal e social.

As falas das crianças, no início da pesquisa-ação, traziam representações socialmente aceitas em relação às condutas esperadas para os gêneros masculino e feminino. Para que as representações pudessem ser problematizadas, era indagado sobre a produção dessas regras. Quem as havia produzido? Não havia outras formas de ser menina e de ser menino?

Ao serem questionadas, aos poucos as crianças conseguiam ver em suas próprias experiências novas possibilidades de ser. No entanto, as questões de gênero estavam relacionadas a regras e padrões sociais, ou seja, elas percebiam as relações de gênero baseadas na vivência desses papéis. Louro,já citada neste artigo, observa que entender o gênero na perspectiva dos papéis limita a percepção de sua dimensão política. A autora analisa essa questão:

Discutir a aprendizagem de papéis masculinos e femininos parece remeter a análise para os indivíduos e para as relações interpessoais. As desigualdades entre os sujeitos renderiam a ser consideradas no âmbito das interações face a face. Ficariam sem exame não apenas as múltiplas formas que podem assumir as masculinidades e as feminilidades, como também as complexas redes de poder que constituem hierarquias entre os gêneros. (1997, p. 24)

Observa também que priorizar a questão dos papéis de gênero traria uma visão reducionista e simplista da constituição dos sujeitos. Em vez de priorizar a questão de ordem pessoal e do âmbito das relações interpessoais, a que nos remete a atribuição dos papéis, a pretensão é "entender o gênero como constituinte da identidade dos sujeitos" (idem, ibidem). Esse foi um dos objetivos das discussões com as crianças.

Para elas, o que era mais premente eram as regras, os padrões sociais do que é considerado "coisa" de menina e de menino. Aos poucos, essas regras e normas passaram a ser minadas. Mesmo assim, era comum ouvir que os gêneros poderiam "transitar" entre o universo masculino e o feminino; apesar disso, estariam demarcando esses espaços entre o que era de um gênero em detrimento do outro. Por exemplo, diziam que meninos podiam brincar com brinquedos "de meninas". O mesmo ocorria com as meninas, que podiam realizar alguma atividade "de menino". Esses ensinamentos sociais fazem parte de várias estratégias educativas, de várias instâncias sociais que demarcam espaços e educam para o gênero e a sexualidade considerados "normais". A demarcação desses binarismos esteve presente na análise das manifestações e desenhos das crianças. Procurou-se questioná-las. Uma das estratégias utilizadas foi pensar e incluir discussões sobre vários tipos de masculinidade e feminilidade. Esses debates trouxeram à tona a relação entre identidade de gênero e identidade sexual, em especial nas falas e piadinhas dos meninos.

Louro (2000, p. 93) nos leva a pensar que gênero e sexualidade constituem dimensões extremamente articuladas, mas que não são sinônimas. Identidade de gê- 
nero remete às várias formas de viver a masculinidade ou a feminilidade; e identidade sexual, a "se referir às formas como os sujeitos vivem os seus prazeres e desejos sexuais". Nesse sentido, as identidades sexuais estariam relacionadas a diversos arranjos e parcerias que os sujeitos inventam e põem em prática para realizar os seus jogos sexuais.

Os meninos, em especial, relutaram mais em desconstruir o modelo único de masculinidade hegemônica. Segundo alguns deles, um menino mais sensível seria considerado homossexual. Às meninas é permitido experienciar novas formas de feminilidade sem a atribuição de que seriam menos mulheres, de acordo com as falas de muitas crianças. É nesse sentido que se procurou entender que a identidade é múltipla e que é uma atribuição cultural. Em virtude desse caráter social, pode ser mudada, tornando-se múltipla, plural, instável, fragmentada.

Ao despertar as crianças acerca da construção das identidades sexuais e de gênero, mediada por livros para a infância e alguns filmes de animação, foi priorizada a discussão sobre algumas marcas e marcadores sociais que afetavam sobremaneira os seus corpos. Um dos exemplos utilizados para essa discussão foi perguntar por que as cores rosa são utilizadas socialmente para designar o feminino, e a azul, para o masculino. As cores, como já exposto, marcam os sujeitos em relação a seu gênero. Junto com elas, outros elementos marcam e demarcam o corpo dos meninos e das meninas, ao reforçar características binárias para os gêneros. No início da pesquisa, essas questões sequer eram pensadas pelas crianças. Aos poucos, novas representações e sentidos a todos os temas tratados passaram a fazer parte das declarações e das demais produções das crianças. Ainda assim, como se viu nos relatos do item anterior, muitas continuaram a pensar de maneira essencialista em relação à construção das identidades de gênero.

Outra questão importante a destacar é o conceito de normalidade presente nas narrativas das crianças. Comumente diziam que ser menina era de um determinado jeito porque isso era "normal". Esse foi um aspecto que mereceu questionamentos. Nessa representação, a norma nem sequer é questionada. Há todo um investimento de poder para consolidá-la como a "verdade". O que se convencionou a ser considerado "normal” marca os sujeitos na sua constituição identitária. Para Silva (2003, p. 83), "normalizar significa eleger - arbitrariamente - uma identidade específica como parâmetro em relação ao qual as outras identidades são avaliadas e hierarquizadas". Dessa forma, o conceito de normalidade foi constantemente questionado com as crianças como produção social. O que é normal? O que é agir de acordo com as normas vigentes? Quem instituiu algo como normal e algo como anormal, desviante? Foram utilizados exemplos cotidianos para tentar questionar esses parâmetros de normalidade que nos afetam e, com isso, passou-se a minar e tensionar os discursos tão naturalizados socialmente e que constituem todos os sujeitos sociais.

Durante a pesquisa, ao coletar falas e representações, constantemente houve interpelações a "perturbar a solidez das certezas" (Louro, 2000, p. 89), a desconfiar do que é dado como natural. Muito se fez e muito se há que fazer. O que se observou é que as crianças se mostraram abertas à construção de novas formas de dar sentido às questões de gênero e às múltiplas possibilidades de constituição de masculinidade e feminilidade, desde que instigadas a pensar e a demonstrar estranhamento sobre o que é proposto como natural. Isso se tornou evidente nas produções dos materiais 
pedagógicos produzidos coletivamente: um livro para a infância e filmes de animação. Com essas ações, a pesquisa atingiu seus objetivos de acreditar na criança como sujeito de cultura, como construtora de conhecimentos sobre si e sobre o mundo.

\section{REFERÊNCIAS}

Brenman, Ilan. Até as princesas soltam pum. Ilustrações de Ionit Zilberman. 3. reimp. São Paulo: Brinque-Book, 2009.25 p.

Britzman, Deborah. O que é esta coisa chamada amor. Educação E̊ Realidade, Porto Alegre, Faculdade de Educação/UFRGS, v. 1, n. 21, jan./jun. 1996.

Cole, Babette. A princesa sabichona. Ilustrações da autora. Tradução de Monica Stahel. 2. tiragem. São Paulo: Livraria Martins Fontes Editora Ltda., 2004. 32 p.

. Príncipe Cinderelo. Ilustrações da autora. Tradução Monica Stahel. 3. tiragem. São Paulo: Livraria Martins Fontes Editora Ltda., 2008. 32 p.

Costa, Marisa Vorraber.Pesquisa-ação, pesquisa participante e política cultural da identidade. In: . (Org.). Caminhos investigativos II. Rio de Janeiro: DP\&A, 2002. p. 93-117.

CRIANÇA NÃo trabalha. Produção de Animare. Direção de Marcelo Branco. Uberlândia,MG: Animare, 2008. DVD (6 min.), son., color.

DISCO VOADOR. Produção de Animare. Direção de Marcelo Branco.Uberlândia,MG: Animare, 2007. DVD (3 min. 44 seg.), son., color.

Estatuto ANIMADo I. Produção de Animare. Direção de Marcelo Branco. Uberlândia, MG: Animare, 2006. DVD (4 min. 42 seg.), son., color.

Estatuto ANIMADO II. Produção de Animare. Direção de Marcelo Branco. Uberlândia, MG: Animare, 2006. DVD (3 min. 37 seg.), son., color.

EU QUERLA ser um monstro. Produção Marão Filmes; Rocambole Produções. Direção Marão. Rio de Janeiro: Rocambole, 2009. DVD (8 min.), son., color.

Foucault, Michel. História da sexualidade. A vontade de saber. v. 1, 12. ed. Rio de Janeiro: Graal, 1997.

.A ordem do discurso. 9. ed. São Paulo: Loyola, 2003.

Goвbi, Márcia. Desenho infantil e oralidade. In: Faria, Ana Lúcia Goulart de et al. (Orgs.). Por uma cultura da infância. Campinas: Autores Associados, 2002. p. 69-92.

ISSO É DE MENINA ou de menino? Produção Universidade Federal de Mato Grosso do Sul e Anima Escola. Direção Tina Xavier. Campo Grande, MS: UFMS, 2009. DVD (3 min.), son., color.

Lenain, Thierry. Ceci tem pipi? Ilustrações de Delphine Durand. Tradução de Heloisa Jahn. 2. reimp. São Paulo: Companhia das Letrinhas, 2006.29 p.

Louro, Guacira Lopes. Gênero, sexualidade e educaşão. Petrópolis: Vozes, 1997.

. Currículo, género e sexualidade. Lisboa: Porto Editora, 2000.

. Conhecer, pesquisar, escrever... Educação, Sociedade e Culturas, Porto, PT, Edições

Afrontamento, v. 1, n. 25, p. 235-245, 2007.

O MENINO Nito.Livros Animados. Produção e direção-geral de Luis Vidal. Direção de André

Glasner.Projeto A cor da Cultura - projeto educativo de valorização da cultura afro-brasileira. 
Parceria Canal Futura, Petrobras, Cidan, TV Globo, SEPPIR. São Paulo: SEPPIR, 2004. DVD (5 min.), son., color.

Oliveira-Formosinho, Júlia (Org.). A escola vista pelas crianças. Porto: Porto Editora, 2008. QUEM É O BOM? Produção de Animare. Direção de Marcelo Branco. Uberlândia, MG: Animare, 2007. DVD (3 min.), son., color. Disponível em:<http://www.youtube.com/watc h?v=8VzAdxeh6Dk\&feature=related $>$. Acesso em: 9 ago. 2011.

Ribeiro, Marcos. Menino brinca de boneca?: conversando sobre o que é ser menino e menina. Ilustrações de Bia Salgueiro. 4. ed. Rio de Janeiro: Salamandra, 1990. 58 p.

Rosa, Sonia. O menino Nito: então, homem chora ou não? Ilustrações de Victor Tavares. 4. ed. Rio de Janeiro: Pallas Editora e Distribuidora Ltda., 2008. 16 p.

RosaAzul no REINo do arco-íris. Produção Universidade Federal de Mato Grosso do Sul e Anima Escola. Direção Tina Xavier. Campo Grande, MS: UFMS, 2009. DVD (5 min.), son., color.

SARmento,Manuel Jacinto. Gerações e alteridade. Educação e Sociedade, Campinas, CEDES, v. 26, n. 91, p. 361-378, maio/ago. 2005.

Scieszka, Jon. O sapo que virou príncipe: continuação. Ilustrações de Steve Johnson. Tradução de Sergio Tellaroli. 6. reimp. São Paulo: Companhia das Letrinhas, 2007. 32 p. Silva, Tomaz Tadeu da. A produção social da identidade e da diferença. In: (Org.). Identidade e diferença. 2. ed. Petrópolis: Vozes, 2003. p. 73-102.

Scott, Joan. Gênero: uma categoria útil de análise histórica. Educação Ẽ Realidade, Porto Alegre, v. 20, n. 2, p. 71-99, jul./dez. 1995.

Xavier Filha, Constantina. A menina e o menino que brincavam de ser... Campo Grande, MS: Editora da UFMS, 1999.

. Entre explosões e cortes na barriga: as curiosidades de Rafael/Entre sementes e cegonhas: as curiosidades de Gabriela. Ilustrações de Marilza Rodrigues. Campo Grande,MS: Editora da UFMS, 2009. 20 p. .As aventuras da princesa pantaneira. Campo Grande: Life Editora, 2012.36 p.

\section{SOBRE A AUTORA}

Constantina Xavier Filha é doutora em educação pela Universidade de São Paulo (USP). Professora da Universidade Federal de Mato Grosso do Sul (UFMS).

E-mail: tinaxav@terra.com.br 


\section{CONSTANTINA XAVIER FILHA}

\section{A menina e o menino que brincavam de ser...: representações de gênero e sexualidade em pesquisa com crianças}

$\mathrm{O}$ artigo tem por objetivo descrever resultados de pesquisa-ação realizada com crianças em uma escola pública na cidade de Campo Grande/MS. As ações fazem parte de pesquisa mais ampla, com apoio do Conselho Nacional de Desenvolvimento Científico e Tecnológico (CNPq), que apresenta duas abordagens teórico-metodológicas: a bibliográfica e a pesquisa-ação. A pesquisa tem o intuito de propiciar momentos de reflexão e problematização sobre as temáticas da sexualidade, gênero e diversidades, mediadas por livros infantis, e produzir coletivamente materiais educativos para/com crianças. O referencial teórico são os dos estudos culturais, dos estudos feministas e de pressupostos foucaultianos. Os dados foram coletados mediante textos escritos e ilustrados, coleta da oralidade das crianças e produção coletiva de materiais educativos. As representações de gênero das crianças evidenciaram atitudes de conformidade às normas sociais e também de resistências e possibilidades de mudanças na construção de ser menino e ser menina.

Palavras-chave: gênero; pesquisa com criança; representações.

The girl and the boy who played to be...: gender and sexuality representations in research with children

This article aims to describe the results of action research conducted with children in a public school in Campo Grande city in Mato do Grosso do Sul State. The actions are part of a wider investigation supported by the National Council for Scientific and Technological Development. Such investigation presents two theoretical and methodological approaches: the literature one and the action research one. The research intends to promote moments of reflection and problematization on the issues of sexuality, gender and diversity, mediated by children's books, and collectively produce educational materials for/with children. The theoretical frameworks are those of cultural studies, geminist studies and foucauldian assumptions. Data were collected through written and illustrated texts, children's oral communication and collective production of educational materials. Gender representations of the children showed attitudes of conformity and resistance to social norms as well as possibilities of changes in the construction of being a boy and being a girl.

Keywords: gender; research with children; representations.

\section{La niña y el niño que jugaban a ser...: representaciones de género y sexualidad en la investigación con niños}

El artículo tiene por objetivo describir los resultados de la investigación-acción realizada con niños en una escuela pública de la ciudad de Campo Grande, Mato Grosso do Sul. Las acciones son parte de una investigación más amplia, con el apoyo del Consejo Nacional de Desarrollo Cientifico y Tecnológico, que presenta dos abordajes teórico-metodológicos: el bibliográfico y la investigación-acción. La investigación tiene la intención de propiciar 
momentos de reflexión y problematización sobre las temáticas de la sexualidad, género y diversidad, mediadas por libros infantiles, y producir colectivamente materiales educativos paralcon los niños. El marco teórico son los de los estudios culturales, de los estudios feministas $y$ de presupuestos foulcautianos. Los datos se han recolectado mediante textos escritos e ilustrados, colecta de la oralidad de los niños y producción colectiva de materiales educativos. Las representaciones de género de los niños evidenciaron actitudes de conformidad a las normas sociales y también de resistencias y posibilidades de cambios en la construcción de ser niño y ser niña.

Palabras clave: género; investigación con niños; representaciones. 